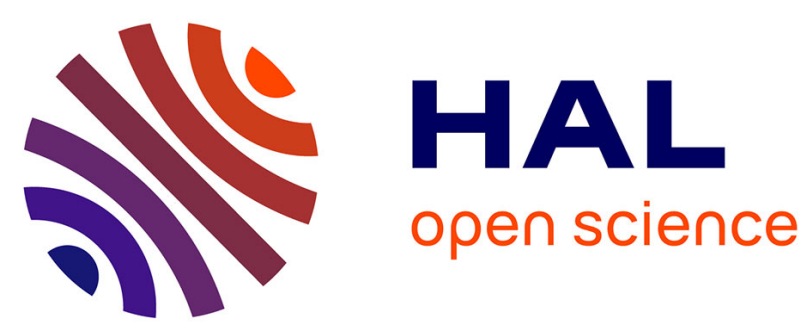

\title{
Comparative study of nonlinear-optical polymers for guided-wave second-harmonic generation at telecommunication wavelengths
}

Tomas Pliska, Wook-Rae Cho, Anne-Claire Le Duff, Vincent Ricci, Akira

Otomo, Michael Canva, Paul Raimond, F. Kajzar

\section{To cite this version:}

Tomas Pliska, Wook-Rae Cho, Anne-Claire Le Duff, Vincent Ricci, Akira Otomo, et al.. Comparative study of nonlinear-optical polymers for guided-wave second-harmonic generation at telecommunication wavelengths. Journal of the Optical Society of America B, 2000, 17 (9), pp.1554-1564. hal-00668006

\section{HAL Id: hal-00668006 \\ https://hal-iogs.archives-ouvertes.fr/hal-00668006}

Submitted on 8 Feb 2012

HAL is a multi-disciplinary open access archive for the deposit and dissemination of scientific research documents, whether they are published or not. The documents may come from teaching and research institutions in France or abroad, or from public or private research centers.
L'archive ouverte pluridisciplinaire HAL, est destinée au dépôt et à la diffusion de documents scientifiques de niveau recherche, publiés ou non, émanant des établissements d'enseignement et de recherche français ou étrangers, des laboratoires publics ou privés. 


\title{
Comparative study of nonlinear-optical polymers for guided-wave second-harmonic generation at telecommunication wavelengths
}

\author{
Tomáš Pliška, ${ }^{*}$ Wook-Rae Cho, Joachim Meier, Anne-Claire Le Duff, ${ }^{\dagger}$ Vincent Ricci, Akira Otomo, ${ }^{\ddagger}$ \\ Michael Canva, ${ }^{\dagger}$ and George I. Stegeman \\ School of Optics, Center for Research and Education in Optics and Lasers, University of Central Florida, \\ P.O. Box 162 700, 4000 Central Florida Boulevard, Orlando, Florida 32816-2700 \\ Paul Raimond and François Kajzar \\ Commissariat à l'Énergie Atomique, Centre d'Études de Saclay, 91191 Gif sur Yvette Cedex, France
}

Received February 29, 2000; revised manuscript received June 5, 2000

\begin{abstract}
We report on the linear and nonlinear-optical properties of 4-dimethylamino-4'-nitrostilbene (DANS), 4-diethylamino-1-nitrobenzyl (DANB), and 4-[N-ethyl- $N$-(2-hydroxyethyl) $]$ amino- $4{ }^{\prime}$-nitroazobenzene) (Disperse Red 1;DR1) side chain polymers whose second-harmonic generation at the telecommunication wavelength of $1.55 \mu \mathrm{m}$ was investigated. Measured ultraviolet-visible-near-infrared spectra were analyzed with an inhomogeneously broadened line-shape model, in particular, in the long-wavelength tail of the electronic transitions, which determines the absorption loss at the second-harmonic wavelength. The nonlinear-optical coefficients were measured at different poling temperatures and poling fields by the Maker fringe technique. On the basis of the measured material parameters we calculated the normalized conversion efficiencies for guided-wave second-harmonic generation at $1.55 \mu \mathrm{m}$. The DR1 polymer exhibited the best nonlinearityabsorption trade-off, with a calculated normalized conversion efficiency of several hundred percent per watt, whereas the figures of merit for DANS and DANB are lower and comparable with each other. (C) 2000 Optical Society of America [S0740-3224(00)01809-9]

OCIS codes: $190.4400,190.4390,190.4410,160.4330,160.5470,160.4890$.
\end{abstract}

\section{INTRODUCTION}

Second-order nonlinear-optical phenomena such as sumand difference-frequency generation, parametric generation, and, most notably, second-harmonic generation have been studied in waveguide configurations in a large variety of materials over the past two decades. Waveguides provide ideal structures for efficient frequency conversion because of the high optical intensity that can be maintained over a long interaction distance. ${ }^{1}$ More-recently emerging applications of parametric mixing include wavelength division multiplexing and cascading of secondorder processes for all-optical signal processing in the 1.3and $1.55-\mu \mathrm{m}$ telecommunication bands. ${ }^{2,3}$

Quasi-phase-matched lithium niobate $\left(\mathrm{LiNbO}_{3}\right)$ waveguides are currently the standard against which all nonlinear-optical waveguides are compared for parametric mixing applications in the near and midinfrared., ${ }^{4,5}$ There are, however, other phase-matchable waveguide systems such as semiconductors and polymers with potentially higher nonlinearities. ${ }^{6-8}$ Chromophore-doped poled polymers have been used for electro-optic applications, in particular for high-speed, low-half-wave voltage modulators. ${ }^{9}$ Poled polymers have also been used for frequency conversion, namely, for second-harmonic generation of blue and green light ${ }^{10,11}$ as well as for parametric interactions and $\chi^{2}: \chi^{2}$ cascading at the telecommunication wavelength of $1.55 \mu \mathrm{m} .^{12}$

The classic inorganic nonlinear-optical materials, e.g., lithium niobate $\left(\mathrm{LiNbO}_{3}\right)$, potassium niobate $\left(\mathrm{KNbO}_{3}\right)$, and potassium titanyl phosphate $\left(\mathrm{KTiOPO}_{4}, \mathrm{KTP}\right)$, are usually used at wavelengths within their transparency range where material absorption can be neglected. The situation is different for many of the currently used nonlinear-optical polymers that have been developed mostly for electro-optic applications at either 1.3 or 1.55 $\mu \mathrm{m}$. In parametric mixing processes, however, there are at least two wavelengths involved. For example, in second-harmonic generation and cascading at $1.55 \mu \mathrm{m}$, the properties of the polymer at both the fundamental and the second-harmonic $(0.775 \mu \mathrm{m})$ wavelengths are relevant. At present, many polymers exhibit much higher losses than inorganic materials at the harmonic wavelength, which limits the effective length and hence the harmonic conversion efficiency.

With a view to taking advantage of the potentially high nonlinearity of organic chromophores, the trade-off between the nonlinear coefficient and linear absorption has been extensively studied, mainly by relating the hyperpolarizability of the chromophore to the wavelength at which the peak of the electronic ultraviolet-visible absorption occurs. ${ }^{13}$ It was found for many chromophore classes that, as a general rule, the hyperpolarizability grows with the redshift of the ultraviolet-visible electronic absorption. ${ }^{13,14}$ However, for second-harmonic generation there is also a trade-off between nonlinearity and absorption at the harmonic wavelength. It is impor- 
tant to realize that the conversion efficiency grows not only with increasing nonlinearity but also with decreasing loss at the harmonic wavelength. ${ }^{15}$ The latter phenomenon depends on both the position of the absorption peak and the width of the absorption band. In only a few investigations has the role of the shape of the absorption band been considered so far. ${ }^{16,17}$ An ideal chromophore for second-harmonic generation should possess the following properties: a significantly redshifted linear absorption peak for enhanced nonlinearity and, at the same time, a narrow absorption bandwidth to minimize the absorption at the second-harmonic wavelength.

One of the best known nonlinear chromophores is 4-dimethylamino- $4^{\prime}$-nitrostilbene (DANS). It has been successfully used in waveguide structures for secondharmonic generation at $1.55 \mu \mathrm{m} .{ }^{18}$ However, DANS has been found to exhibit relatively high absorption losses at the second-harmonic wavelength ${ }^{16}$ and rather poor photostability. ${ }^{19}$ Therefore we have undertaken the present study of the linear absorption and nonlinear-optical coefficients of two other nonlinear chromophores in addition to DANS, namely, 4diethylamino-1-nitrobenzyl (DANB) and 4-[ $N$-ethyl- $N$ (2-hydroxyethyl)] amino-4' -nitroazobenzene (Disperse Red 1; DR1). These three chromophores represent three different classes of nonlinear organic compound, all of which have been studied in the literature for their molecular properties, i.e., benzenes (DANB), stilbenes (DANS), and azobenzenes (DR1). Here, we have investigated their absorption spectra and nonlinearities to discuss their potential use in polymeric integrated optical devices for secondharmonic generation and cascading at $1.55 \mu \mathrm{m}$, and we shall calculate their second-harmonic conversion efficiencies in guided-wave interactions.

\section{THEORETICAL BACKGROUND}

A. Molecular and Macroscopic Properties of NonlinearOptical Polymers

The relation between molecular and macroscopic properties of nonlinear-optical polymers was discussed previously in the literature. ${ }^{20,21}$ To calculate the linear and nonlinear-optical susceptibilities $\chi_{i j}^{(1)}$ and $\chi_{i j k}^{(2)}$, respectively, from the molecular linear polarizability $\alpha_{I J}$ and hyperpolarizability $\beta_{I J K}$, one usually assumes that the molecule is rod-like with $m m \infty$ symmetry, and its response is assumed to be dominated by the tensor elements along the charge transfer axis ( $Z$ axis), i.e., $\alpha_{Z Z}$ and $\beta_{Z Z Z}$. The indices $(I, J, K)$ denote molecular coordinates, and $(i, j, k)$ are the laboratory frame coordinates. The second-order nonlinear-optical tensor $d_{i j k}$ for secondharmonic generation contains then only the elements $d_{z z z} \equiv d_{33}$ and $d_{x z x}=d_{z x x} \equiv d_{31}$, if Kleinman's symmetry rule applies, given by

$$
\begin{aligned}
d_{31}(-2 \omega, \omega, \omega)= & 1 / 2 N f_{z}{ }^{2 \omega} f_{x}{ }^{\omega} f_{x}{ }^{\omega} \beta_{Z Z Z}(-2 \omega, \omega, \omega) \\
& \times\left\langle 1 / 2 \cos \theta \sin ^{2} \theta\right\rangle \\
d_{33}(-2 \omega, \omega, \omega)= & 1 / 2 N f_{z}{ }^{2 \omega} f_{z}{ }^{\omega} f_{z}{ }^{\omega} \beta_{Z Z Z}(-2 \omega, \omega, \omega) \\
& \times\left\langle\cos ^{3} \theta\right\rangle
\end{aligned}
$$

where $N$ represents the number density of chromophores, $f_{i}$ are the local field correction factors, and $\theta$ is the angle between the molecular dipole moment and the electric poling field, which defines the $z$ axis in the laboratory frame. Angle brackets indicate the thermodynamic average over all molecular orientations. The local field at optical frequencies can be described in the Lorenz-Lorentz approximation in which the molecule is assumed to be in a spherical environment, and the $f$ tensor contains only diagonal elements $f_{i}{ }^{\omega}$, given by

$$
f_{i}^{\omega}=\frac{n_{i}{ }^{2}(\omega)+2}{3},
$$

where $n_{i}$ is the refractive index at frequency $\omega$. For static poling fields the correction factor $f_{i}{ }^{0}$ is given by the Onsager expression

$$
f_{i}^{0}=\frac{\epsilon_{i}\left(n_{i}{ }^{2}+2\right)}{n_{i}{ }^{2}+2 \epsilon_{i}},
$$

where $\epsilon_{i}$ denotes the static dielectric constant. ${ }^{22,23}$ For practical purposes the small dispersion and birefringence of the refractive indices in the off-resonant regime allow the approximation $f_{x}{ }^{\omega} \approx f_{z}{ }^{\omega} \approx f_{z}{ }^{2 \omega} \equiv f$, which permits us to define the quantity $d_{33 \text {,max }}$ in Eqs. (1) and (2) by

$$
d_{33, \max } \equiv 1 / 2 N f^{3} \beta_{Z Z Z} \text {. }
$$

$d_{33 \text {,max }}$ represents the maximum attainable nonlinearoptical coefficient for the case of perfect polar order, $\left\langle\cos ^{3} \theta\right\rangle=1$.

To describe the orientational average of chromophores in a poled polymer film ${ }^{21}$ we use for thermodynamic averaging a mean field potential $U(\theta)$ given by the sum of the energy of a permanent dipole moment $\boldsymbol{\mu}_{0}$ and a linearly induced dipole moment $\boldsymbol{\mu}_{\text {ind }}$ in a local field $\mathbf{E}^{\prime}$ :

$U(\theta)=-\left(\boldsymbol{\mu}_{0}+\boldsymbol{\mu}_{\text {ind }}\right) \mathbf{E}^{\prime}=-\mu_{0, I} E_{I}{ }^{\prime}-1 / 2 E_{I}{ }^{\prime} \alpha_{I J} E_{J}{ }^{\prime}$.

The $\theta$-dependent part of the energy of the induced dipole moment can be rewritten as $-1 / 3 \Delta \alpha E^{\prime 2} P_{2}(\cos \theta)$, where $P_{2}(\cos \theta)=\left(3 \cos ^{2} \theta-1\right) / 2$ is the second-order Legendre polynomial and $\Delta \alpha \equiv \alpha_{Z Z}-\alpha_{X X} \approx \alpha_{Z Z}$. The calculation of orientational averages yields, as its main result, a linear relation between the nonlinearity $d_{33}$ and the external poling field $E$ in the low-field limit ${ }^{20}$ :

$$
d_{33} \approx \frac{N f_{z}{ }^{2 \omega} f_{z}{ }^{\omega} f_{z}{ }^{\omega} f_{z}{ }^{0} \beta_{Z Z Z} \mu_{0, Z} E}{10 k T} .
$$

In addition, a simple relation between $d_{31}$ and $d_{33}$ exists:

$$
d_{33} \approx 3 d_{31} \text {. }
$$

This relation is of practical importance because it implies that in most devices $d_{33}$ should be used as the active nonlinear coefficient.

\section{B. Inhomogeneously Broadened Absorption Profiles}

The linear absorption of a nonlinear-optical polymer in the wavelength range $0.3-1.6 \mu \mathrm{m}$ is dominated by two mechanisms: in the ultraviolet and the visible parts of the spectrum the electronic resonances of the chromophore are responsible for strong transition bands, 
whereas for wavelengths above $1 \mu \mathrm{m}$ most of the absorption is due to much weaker vibrational overtones of $\mathrm{C}-\mathrm{H}$ bonds. ${ }^{24}$

Assuming first unpoled isotropic polymer films and thus using scalar notation, we can obtain the linear power attenuation coefficient $\alpha$ from the relations $n^{2}(\omega)=1$ $+\chi^{(1)}(\omega)$ at optical frequencies and $\alpha(\omega)=2 \omega /$ $c \operatorname{Im}[n(\omega)]$. An inhomogeneously broadened linear susceptibility model is appropriate to reproduce the details of the absorption band. ${ }^{16}$ In this model the linear susceptibility $\chi^{(1)}(\omega)$ is described by

$$
\begin{aligned}
\chi^{(1)}(\omega)= & \frac{N f^{\omega} \Theta}{\sqrt{\pi} \epsilon_{0} \hbar} \sum_{n} \frac{\mu_{0 n}{ }^{2}}{\Delta \omega_{n}} \int_{-\infty}^{+\infty}\left(\frac{1}{\omega_{0 n}{ }^{\prime}-\omega+i \Gamma_{n} / 2}\right. \\
& \left.+\frac{1}{\omega_{0 n}{ }^{\prime}+\omega-i \Gamma_{n} / 2}\right) \\
& \times \exp \left[-\left(\frac{\omega_{0 n}{ }^{\prime}-\omega_{0 n}}{\Delta \omega_{n}}\right)^{2}\right] \mathrm{d}\left(\omega_{0 n}{ }^{\prime}-\omega_{0 n}\right),
\end{aligned}
$$

where $\Theta$ is a molecular orientational factor $(\Theta=1 / 3$ for randomly oriented dipoles), $\mu_{0 n}$ is the transition dipole moment from the ground to the $n$th excited state at frequency $\omega_{0 n}$, and $\Gamma_{n}$ is the population decay rate of the $n$th level. The inhomogeneous broadening is described by an asymmetric Gaussian function of the form

$$
G_{n}\left(\omega_{0 n}{ }^{\prime}-\omega_{0 n}\right)=\frac{1}{\sqrt{\pi} \Delta \omega_{n}} \exp \left[-\left(\frac{\omega_{0 n}{ }^{\prime}-\omega_{0 n}}{\Delta \omega_{n}}\right)^{2}\right],
$$

where the asymmetric linewidth $\Delta \omega_{n}$ is modeled by

$$
\frac{1}{\Delta \omega_{n}}=\frac{1}{\Delta \omega_{n}^{0}}\left[1-\xi_{n}+\xi_{n}\left(\frac{\omega_{0 n}}{\omega}\right)^{2}\right]
$$

and $\xi_{n}$ is the asymmetry parameter. According to Eq. (9) the linear susceptibility is described as a sum over the transitions from the ground state to the excited states. The line shape of each of these transitions is given by the convolution of an asymmetric Gaussian function dominating the line shape near the absorption peak and a Lorentzian function prevailing in the tail of the spectrum.

Experimentally, one fits the imaginary part of $\chi^{(1)}(\omega)$ to the measured absorption spectrum to evaluate the unknown parameters $\omega_{0 n}, \mu_{0 n}, \Gamma_{n}, \Delta \omega_{n}{ }^{0}$, and $\xi_{n}$. In the measured absorption spectrum, usually only the peak of the $0-1$ transition is sufficiently well resolved. Thus the fit yields reliable values only for $\omega_{01}, \mu_{01}$, and $\Delta \omega_{1}{ }^{0} \cdot \Gamma_{1}$ is uncertain because it is small compared with $\Delta \omega_{1}{ }^{0}$. All other parameters $(n \geqslant 2)$ are used strictly for fitting purposes without any further physical significance being assigned to them.

One can derive orientational effects on the absorption spectrum by calculating the orientational average of the chromophores and its corresponding linear susceptibility. One finds for the absorption coefficients $\alpha_{a, \|}$ and $\alpha_{a, \perp}$ for light polarized parallel and perpendicular, respectively, to the axis defined by the poling field ( $z$ axis) the expressions

$$
\begin{aligned}
\alpha_{a, \|}(\omega) & =\frac{\omega}{c n_{z}(\omega)} N f_{z}{ }^{\omega} \operatorname{Im}\left[\alpha_{Z Z}(\omega)\right]\left\langle\cos ^{2} \theta\right\rangle, \\
\alpha_{a, \perp}(\omega) & =\frac{\omega}{c n_{x}(\omega)} N f_{x}{ }^{\omega} \operatorname{Im}\left[\alpha_{Z Z}(\omega)\right]\left\langle 1 / 2 \sin ^{2} \theta\right\rangle .
\end{aligned}
$$

Here, we have assumed that the absorption is dominated by the chromophore contribution to the linear susceptibility. Equations (12) and (13) provide a link between the molecular polarizability and the macroscopic absorption of a poled polymer. In an unpoled isotropic polymer film one finds that $\left\langle\cos ^{2} \theta\right\rangle=\left\langle 1 / 2 \sin ^{2} \theta\right\rangle=1 / 3, n_{x}=n_{z}, f_{x}$ $=f_{z}$, and a corresponding isotropic absorption coefficient $\alpha_{a, \text { iso }}$ given by

$$
\alpha_{a, \text { iso }}(\omega)=\frac{1}{3} \frac{\omega}{c n(\omega)} N f^{\omega} \operatorname{Im}\left[\alpha_{Z Z}(\omega)\right] .
$$

In the wavelength range where chromophore absorption dominates, Eqs. (12)-(14) allow us to determine the absorption coefficient for a given poling field from measurements of the absorption spectrum of an unpoled film. In most practical devices that use the $d_{33}$ nonlinear coefficient, the absorption will be given by $\alpha_{a, \|}$.

\section{Second-Harmonic Generation in Channel Waveguides}

The normalized second-harmonic conversion efficiency $\eta$ in a channel waveguide of length $L$ is given by

$$
\eta \equiv \frac{P_{2 \omega}(L)}{\left[P_{\omega}(0)\right]^{2}}=\frac{2 \omega^{2}}{\epsilon_{0} c^{3}} \frac{d_{\mathrm{eff}}^{2}}{N_{2 \omega}\left(N_{\omega}\right)^{2}} \Gamma h\left(\Delta \beta, \alpha_{\omega}, \alpha_{2 \omega}, L\right) .
$$

$P_{2 \omega}(L)$ is the second-harmonic power, $P_{\omega}(0)$ is the fundamental power launched into the guide, $d_{\text {eff }}$ denotes the effective nonlinear coefficient, $\Gamma$ is the overlap integral (inverse effective cross section), $\Delta \beta=\beta_{2 \omega}-2 \beta_{\omega}$ is the phase mismatch, and $\alpha_{\omega}$ and $\alpha_{2 \omega}$ are the losses at the fundamental and the second-harmonic wavelengths, respectively. Under phase-matched conditions $(\Delta \beta=0)$ the dependence on loss is contained in the expression

$$
h\left(\alpha_{\omega}, \alpha_{2 \omega}, L\right)=L^{2} \exp \left[-\left(\frac{\alpha_{2 \omega}}{2}+\alpha_{\omega}\right) L\right] \frac{\left(\sinh \frac{\Delta \alpha L}{2}\right)^{2}}{\left(\frac{\Delta \alpha L}{2}\right)^{2}},
$$

with $\Delta \alpha=\alpha_{2 \omega} / 2-\alpha_{\omega} . \quad h$ will exhibit a maximum as a function of $L$ at a length $L_{\max }$ of

$$
L_{\max }=\frac{1}{\Delta \alpha} \ln \left(\frac{\alpha_{2 \omega}}{2 \alpha_{\omega}}\right) .
$$

This maximum useful length has been shown to be of the order of several millimeters in present polymer waveguides. $^{18}$ In addition to absorption loss, the guided light can be attenuated by scattering losses owing to imperfections at the guide interfaces. ${ }^{25}$ We thus write the total waveguide loss $\alpha$ as the sum of the absorption and scattering losses $\alpha=\alpha_{a}+\alpha_{s}$. 


\section{MATERIALS}

Since the discovery of the first good organic nonlinearoptical chromophores such as nitroaniline and nitropyridine derivatives, many new materials have been investigated. Most of the research has concentrated on materials with two or more benzene rings, such as stilbenes and azobenzenes, ${ }^{8}$ that are superior with regard to their molecular hyperpolarizability. However, because of the nonlinearity-transparency trade-off, chromophores with optimized nonlinearity are not necessarily the most suitable ones for parametric mixing applications; therefore, simpler compounds with, for example, only one benzene ring as a $\pi$-electron system also merit consideration. Whereas both DANS and DR1 are well known for their large hyperpolarizability, ${ }^{26}$ the use of the DANB chromophore in the present study was driven by the wellestablished high transparency in the visible and in the near infrared of single benzene ring systems such as ni-

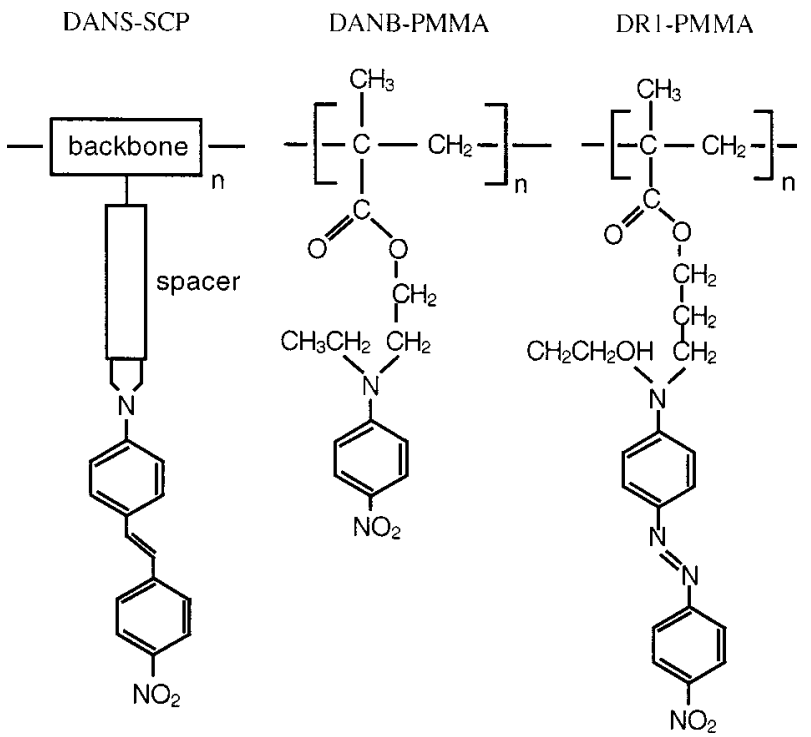

Fig. 1. Chemical structures of DANS, DANB, and DR1 side chain polymers. troanilines and related compounds. Waveguiding structures for second-harmonic generation at $1.55 \mu \mathrm{m}$ have been proposed for all three materials; ${ }^{12,27-29}$ however, all devices were far from being optimized. We have thus performed this study to assess their potential further.

The structures of the three side-chain polymers are displayed in Fig. 1. The backbone used for the DANS sidechain polymer (DANS-SCP) was polycarbonate, whereas DANB and DR1 were attached to poly(methyl methacrylate) (PMMA). The material and molecular parameters of the chromophores used throughout this study are listed in Tables 1 and 2, respectively. Because the molecular data for DANB were not available we utilized the corresponding parameters for 4-dimethylamino-1-nitrobenzyl.

We calculated the Lorentz correction factors at optical frequencies given by Eq. (3) by using the indices of refraction listed in Table 1. Static local field correction factors $f_{z}{ }^{0}$ at the poling temperature [Eq. (4)] were calculated on the basis of dielectric constant data for polycarbonates and PMMA from the literature ${ }^{30,31}$ listed in Table 1. For the DANS-SCP we used $f_{z}{ }^{0}=1.6 \pm 0.1$; for DANBPMMA and DR1-PMMA, $f_{z}{ }^{0}=1.8 \pm 0.1$.

\section{EXPERIMENTS}

\section{A. Measurement of Linear Absorption Spectra}

Sample preparation started with spin coating the polymer solution onto the substrate and subsequent curing of the polymer layer close to the glass-transition temperature for $\sim 12 \mathrm{~h}$ to remove residual solvent.

Absorption spectra of the polymers were obtained from absorbance measurements with a transmission spectrophotometer of thin unpoled films $(\sim 0.1$ to $\sim 3 \mu \mathrm{m}$ thick $)$ cast upon fused-silica substrates. However, only the strong ultraviolet-visible electronic absorption can be measured by this method, because for its infrared tail (absorption coefficient below $\sim 1000 \mathrm{~cm}^{-1}$ ) transmission spectroscopy does not provide the required resolution. Because of the limited availability of polymer material it was impossible to prepare bulk samples that would pro-

Table 1. Properties of Polymers Used in This Paper

\begin{tabular}{|c|c|c|c|}
\hline Property & DANS-SCP & DANB-PMMA & DR1-PMMA \\
\hline Chromophore (wt. \%) & 43 & 65 & 24 \\
\hline Number density of chromophores $\left(\mathrm{m}^{-3}\right)$ & $1.3 \times 10^{27}$ & $2.6 \times 10^{27}$ & $0.5 \times 10^{27}$ \\
\hline Chromophore-to-backbone monomer ratio & Not applicable & $1: 1$ & $1: 10$ \\
\hline Glass-transition temperature $T_{g}\left({ }^{\circ} \mathrm{C}\right)$ & 142 & 98 & 131 \\
\hline Index of Refraction $n_{\omega}$ at $1.55 \mu \mathrm{m}$ & 1.61 & 1.56 & 1.54 \\
\hline Index of Refraction $\omega_{2 \omega}$ at $0.775 \mu \mathrm{m}$ & 1.65 & 1.58 & 1.56 \\
\hline Dielectric constant $\epsilon$ at poling temperature (Ref.) & 3.0 at $135^{\circ} \mathrm{C}(30)$ & 5.6 at $100^{\circ} \mathrm{C}(31)$ & 5.7 at $120^{\circ} \mathrm{C}$ \\
\hline
\end{tabular}

Table 2. Molecular Parameters of Chromophores Used in This Paper ${ }^{a}$

\begin{tabular}{lrr}
\hline \multicolumn{1}{c}{ Parameter } & DANS & DANB $^{b}$ \\
\hline $\begin{array}{l}\text { Ground-state dipole moment } \mu_{0, Z} \text { in solution } \\
(\mathrm{Cm})(\text { value in D) }\end{array}$ & $2.4 \times 10^{-29}(7.2)$ & $2.4 \times 10^{-29}(7.1)$ \\
\begin{tabular}{l} 
Linear polarizability $\alpha_{Z Z}$ in solution $\left(\mathrm{Fm}^{2}\right)$ \\
\hline
\end{tabular} & $5.0 \times 10^{-39}$ & $2.6 \times 10^{-39}$ \\
\hline
\end{tabular}

${ }^{a}$ According to Ref. 26. Solvent, dimethyl sulfoxide (DMSO).

${ }^{b}$ Values quoted for 4-dimethylamino-1-nitrobenzyl. 
vide the necessary absorption length. Moreover, bulk polymers can exhibit different absorption properties from thin polymer films. Therefore, to estimate the absorption coefficient in the infrared, we spin coated thin (approximately $1.5-3-\mu \mathrm{m}$-thick) layers of polymer onto thermally oxidized silicon wafers $\left(\mathrm{SiO}_{2}\right.$ layer thickness, $\sim 3$ $\mu \mathrm{m}$; index of refraction, 1.45). After cleaving the faces to facilitate end fire coupling we used the polymer films as planar waveguides for which the propagation loss was measured by the cutback method. The waveguide propagation loss in such a thin-film guide originates from three phenomena: absorption, volume scattering, and interface scattering. Knowledge of the guide parameters (indices of refraction, thickness, root-mean-square surface roughness of $\sim 3 \mathrm{~nm}$ as measured by atomic-force microscopy) allows us to separate interface scattering losses by using the expression given by Tien. ${ }^{25}$ The remaining loss, caused by absorption and volume scattering, yields a good estimate for the intrinsic material loss. The accuracy of this measurement is $\sim 10 \%$, with a minimum resolution of $0.1 \mathrm{~cm}^{-1}$.

We used the following laser sources to obtain propagation loss data in planar waveguides: $\mathrm{an}^{+} \mathrm{Ar}^{+}$ion laser $(0.515 \mu \mathrm{m})$, a He-Ne laser $(0.543,0.594$, and $0.633 \mu \mathrm{m})$, an AlGaAs diode laser $(0.78 \mu \mathrm{m})$, a Nd:YAG laser (1.06 and $1.32 \mu \mathrm{m}$ ), and a $\mathrm{NaCl}: \mathrm{OH}^{-}$color-center laser (tunable from 1.50 to $1.65 \mu \mathrm{m}$ ).

Although our model, given by Eqs. (9)-(11), describes the spectrum as a function of photon energy (frequency), we prefer to plot the data as a function of wavelength, which is more appropriate for our application-oriented approach. Absorption coefficients are given in units of inverse centimeters $\left(\mathrm{cm}^{-1} ; 1 \mathrm{~cm}^{-1}=4.34 \mathrm{~dB} \mathrm{~cm}^{-1}\right)$.

\section{B. Poling Techniques}

Two configurations were used for poling: parallel-plate and in-plane poling. For parallel-plate poling 1.5-3- $\mu \mathrm{m}$ thick polymer films were spin coated onto indium tin oxide-coated fused-silica or borosilicate glass substrates. Approximately 150-nm-thick $\mathrm{Al}$ electrodes with an approximate size of $1 \mathrm{~cm} \times 1 \mathrm{~cm}$ were deposited on top of the films by thermal evaporation. The voltage was then applied between the bottom indium tin oxide and the top $\mathrm{Al}$ electrodes. The procedure for in-plane poling was reported previously in Ref. 32 . We prepared samples by patterning two $\mathrm{Al}$ electrodes of 250-nm thickness with a gap of $20 \mu \mathrm{m}$ onto fused-silica substrates and spin coating the nonlinear polymer onto the substrates. To prevent arcing along the air-film interface we spun an additional cladding layer of polycarbonate polymer of $15-\mu \mathrm{m}$ thickness on top of the sample.

The parallel-plate geometry offers the advantages of ease of fabrication and availability of a large area for measurement. However, poling at fields above 150 $\mathrm{V} \mu \mathrm{m}^{-1}$ is critical as the samples become more susceptible to electrical breakdown. We observed that, as a general rule, higher fields can be applied to thicker samples. With the available DANB-PMMA solution we were able to prepare samples of a maximum 1.5- $\mu \mathrm{m}$ thickness and to reach an external poling field of $95 \mathrm{~V} \mu \mathrm{m}^{-1}$. The largest layer thickness prepared with the DR1-PMMA polymer was $2.5 \mu \mathrm{m}$, and the maximum poling field reached was
$150 \mathrm{~V} \mu \mathrm{m}^{-1}$. Higher poling fields, up to $370 \mathrm{~V} \mu \mathrm{m}^{-1}$, can be obtained with the in-plane poling geometry, as was previously shown with DANS-SCP. ${ }^{32}$ However, the small electrode spacing limits the poled area available for the measurements and requires more-complicated experimental procedures.

Poling was performed in a furnace in ambient atmosphere. Once the sample reached the poling temperature close to the glass-transition temperature, the voltage was carefully ramped at a rate of $\sim 10 \mathrm{~V} \mathrm{~min}^{-1}$. The samples were kept at the poling temperature for $\sim 2 \mathrm{~h}\left(135^{\circ} \mathrm{C}\right.$ for DANS-SCP, $100^{\circ} \mathrm{C}$ for DANB-PMMA, and $120^{\circ} \mathrm{C}$ for DR1-PMMA). Then they were slowly cooled to room temperature at a rate of $\sim 0.5^{\circ} \mathrm{C} \mathrm{min}^{-1}$ with the voltage applied. Thereafter, for the parallel-plate poled samples the top electrode was etched off by use of a mixture of phosphoric, acetic, and nitric acids.

\section{Measurement of Nonlinear-Optical Coefficients}

We used a standard Maker fringe setup to measure the nonlinear coefficients of the poled polymer films. A $y$-cut quartz plate was used as a reference with a value of $d_{11}$ $=0.29 \mathrm{pm} \mathrm{V}^{-1}$ at a wavelength of $1.58 \mu \mathrm{m}$ to calibrate the measurement (equivalent to $d_{11}=0.30 \mathrm{pm} \mathrm{V}^{-1}$ at $1.064 \mu \mathrm{m}){ }^{33}$ The $1.58-\mu \mathrm{m}$ fundamental radiation was generated by Raman shifting of the output of a frequencydoubled $(0.532-\mu \mathrm{m}) Q$-switched Nd:YAG laser in a hydrogen cell (pulse duration, $10 \mathrm{~ns}$; pulse energy at $1.58 \mu \mathrm{m}$, $10 \mu \mathrm{J})$. The transmitted fundamental beam was blocked by a set of filters, whereas the second-harmonic signal was detected with a photomultiplier tube. Using inplane poled samples, we were able to measure directly the nonlinear coefficient $d_{33}$, whereas the parallel-plate geometry yielded more-accurate values for $d_{31}$. In the latter case we used expression (8) to obtain the value of $d_{33}$. The experimental uncertainty of the measured nonlinear coefficient was $\pm 15 \%$, with a minimum resolution of 0.1 $\mathrm{pm} \mathrm{V}^{-1}$.

\section{RESULTS AND DISCUSSION}

\section{A. Linear Absorption Spectra and Nonlinear-Optical Coefficients}

The absorption spectrum of DANS-SCP, previously published in Ref. 16, is shown here in Fig. 2 on a semilogarithmic scale. The fit to the inhomogeneously broadened absorption profile, described by Eq. (9), is indicated by the solid curve; its Gaussian part is represented by the dashed curve. Four transitions were used to fit the spectrum. We also measured the absorption coefficient at the second-harmonic wavelength of $0.78 \mu \mathrm{m}$ in a $2.5-\mu \mathrm{m}$-thick planar waveguide, indicated by the filled diamond in Fig. 2. The measured absorption spectra of DANB-PMMA and DR1-PMMA are plotted in Figs. 3 and 4, respectively. For these two polymers we used two transitions to fit the spectra.

In Table 3 we have listed the measured absorption data, where $\lambda_{01}$ is the peak absorption wavelength, $\Delta \omega_{0}$ is the fitted Gaussian linewidth of the $0-1$ state transition, and $\alpha_{a \text {,iso }}(2 \omega)$ is the absorption coefficient at the secondharmonic wavelength of $0.78 \mu \mathrm{m}$ for the unpoled polymer. The absorption spectrum of DANS-SCP (Fig. 2) is charac- 


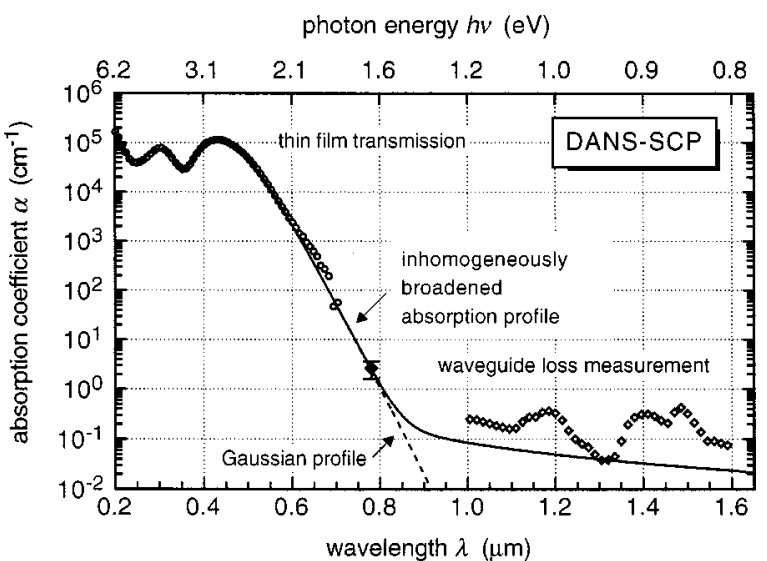

Fig. 2. Ultraviolet-visible-near-infrared absorption spectrum of DANS-SCP. Open circles, data measured by transmission spectroscopy of an unpoled thin film (thickness, $0.2 \mu \mathrm{m}$ ); open diamonds, data measured in a planar waveguide (from Ref. 16). Filled diamond, loss measured in a planar DANS waveguide of $2.5-\mu \mathrm{m}$ thickness at a wavelength of $0.78 \mu \mathrm{m}$. Solid curve, fitted inhomogeneously broadened absorption profile according to Eq. (9); dashed curve, Gaussian part of the inhomogeneously broadened line.

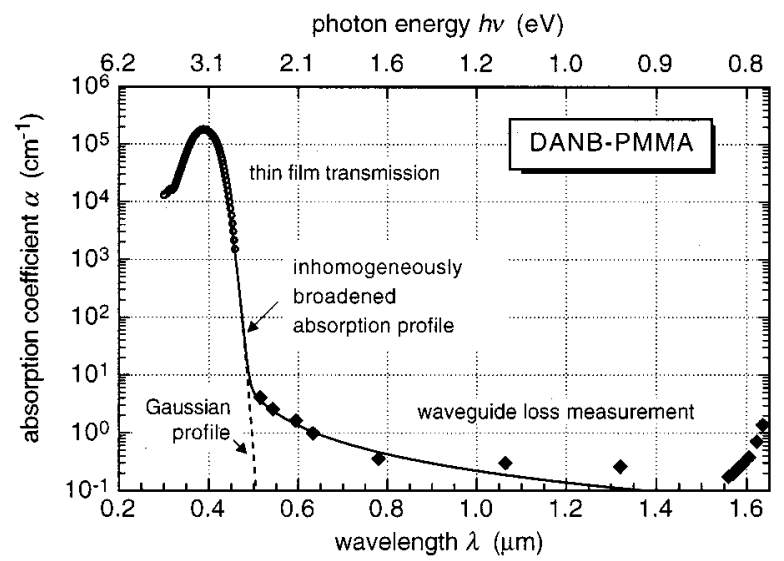

Fig. 3. Ultraviolet-visible-near-infrared absorption spectrum of DANB-PMMA. Open circles, data measured by transmission spectroscopy of an unpoled thin film (thickness $0.6 \mu \mathrm{m}$ ); filled diamonds, data measured in a planar waveguide (thickness, 1.6 $\mu \mathrm{m})$. Curves, same meaning as for Fig. 2.

terized by a broad Gaussian linewidth, which is responsible for the relatively strong absorption of (2.5 $\pm 0.3) \mathrm{cm}^{-1}$ at the second-harmonic wavelength of 0.78 $\mu \mathrm{m}$. The fitted Gaussian linewidth in the absorption spectrum of DANB-PMMA (Fig. 3) is significantly narrower than the one for DANS-SCP. At $0.78 \mu \mathrm{m}$, DANBPMMA is essentially transparent, most of the measured loss being due to scattering. However, this high transparency in the visible and infrared is associated with a pronounced blueshift of the electronic transitions, which, in general, results in smaller hyperpolarizabilities. ${ }^{13}$ DR1-PMMA (Fig. 4), finally, peaks at the longest wavelength among the three polymers considered here, with a relatively narrow Gaussian bandwidth. The measured absorption coefficient at $0.78 \mu \mathrm{m}$ is $(0.3 \pm 0.1) \mathrm{cm}^{-1}$. Our measurement of the absorption of DR1-PMMA is in very good agreement with the results obtained by photothermal deflection spectroscopy and reported in Ref. 24 for a similar DR1-PMMA polymer.
Comparison of the three absorption spectra shows that the chromophores experience different amounts of inhomogeneous broadening. Whereas for DANS-SCP the wavelength of $0.78 \mu \mathrm{m}$ falls onto the Gaussian part of the absorption line, the same wavelength is on the Lorentzian branch of the spectrum for DANB-PMMA and for DR1PMMA. DR1-PMMA exhibits a nearly ideal absorption characteristic for second-harmonic generation at $1.55 \mu \mathrm{m}$ : a significantly redshifted absorption maximum combined with a narrow bandwidth, so the second-harmonic wavelength falls right onto the short-wavelength end of the transparency region.

In the fundamental wavelength window, near $1.55 \mu \mathrm{m}$, the absorption spectrum is dominated by the vibrational overtone bands of the $\mathrm{C}-\mathrm{H}$ bonds that occur in any organic polymer in which $\mathrm{C}-\mathrm{H}$ bonds are present. It is independent of the chromophores incorporated in the polymer matrix and of their number density. ${ }^{24}$ To illustrate the effect of overtone absorption, we have plotted in Fig. 5 the measured propagation loss in a 1.5- $\mu \mathrm{m}$-thick DANBPMMA waveguide for wavelengths of $1.55-1.65 \mu \mathrm{m}$. It is evident that a pronounced increase in attenuation occurs for wavelengths above $1.6 \mu \mathrm{m}$, limiting the useful wavelength window in the telecommunication band.

The effect of poling on the absorption coefficient is shown in Fig. 6. This measurement was performed on in-plane poled DANS-SCP samples at the wavelength of $0.458 \mu \mathrm{m}$, close to the absorption maximum. The curves were fitted according to Eqs. (12) and (13) with the isotropic absorption coefficient $\alpha_{a \text {,iso }}$ [Eq. (14)] as the only adjustable parameter (fitted value, $\alpha_{a \text {,iso }}=1.1$ $\times 10^{5} \mathrm{~cm}^{-1}$ ). The poling-induced dichroism is clearly evident from this measurement. For practical external poling fields smaller than $300 \mathrm{~V} \mu \mathrm{m}^{-1}$, the increase of the absorption parallel to the polarization direction is smaller than $30 \%$.

The measured nonlinear coefficients $d_{33}$ of DANS-SCP, DANB-PMMA, and DR1-PMMA are shown in Figs. 7(a), 7(b), and 7(c), respectively. The data are plotted as a function of the poling field with the respective Onsager correction factors. The curves in Figs. 7(a) and 7(c) represent fits to Eq. (2) and expression (7), respectively.

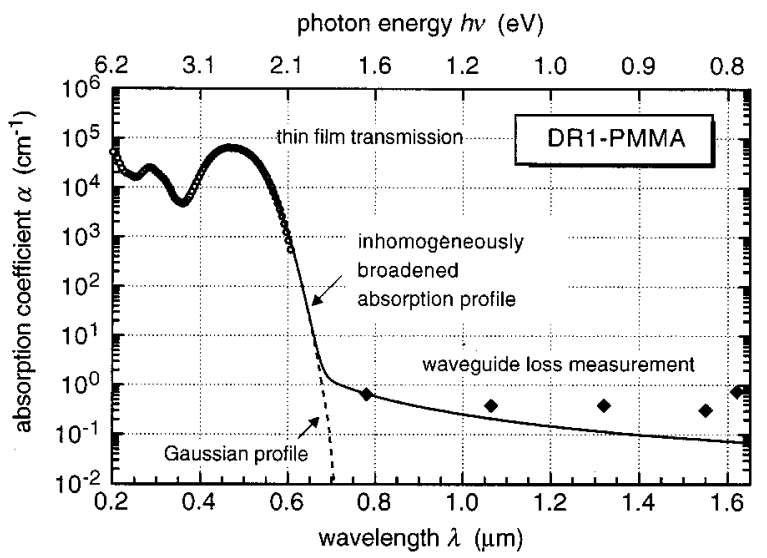

Fig. 4. Ultraviolet-visible-near-infrared absorption spectrum of DR1-PMMA. Open circles, data measured by transmission spectroscopy of an unpoled thin film (thickness, $1.1 \mu \mathrm{m}$ ); filled diamonds, data measured in a planar waveguide (thickness, 1.5 $\mu \mathrm{m})$. Curves, same meaning as for Fig. 2. 
Table 3. Measured Absorption Characteristics and Nonlinear-Optical Properties and Calculated Second-Harmonic Conversion Efficiencies of the Polymers Used in This Paper

\begin{tabular}{|c|c|c|c|}
\hline Property & DANS-SCP & DANB-PMMA & DR1-PMMA \\
\hline$\lambda_{01}(\mu \mathrm{m})$ & 0.430 & 0.384 & 0.467 \\
\hline$\Delta \omega_{0}\left(\mathrm{~s}^{-1}\right)$ & $(6.6 \pm 0.6) \times 10^{14}$ & $(4.2 \pm 0.4) \times 10^{14}$ & $(5.8 \pm 0.6) \times 10^{14}$ \\
\hline$\alpha_{a, i s o}(2 \omega)\left(\mathrm{cm}^{-1}\right)$ at $\lambda=0.78 \mu \mathrm{m}$ & $2.5 \pm 0.3$ & $0.1 \pm 0.1$ & $0.3 \pm 0.1$ \\
\hline$d_{33}\left(\mathrm{pm} \mathrm{V}^{-1}\right)$ at $E=150 \mathrm{~V} \mu \mathrm{m}^{-1}$ & $14.2 \pm 0.6$ & $6.8 \pm 0.1$ & $7.3 \pm 0.4$ \\
\hline$d_{33, \max }\left(\mathrm{pm} \mathrm{V}^{-1}\right)$ & $73 \pm 15$ & $29 \pm 6$ & $27 \pm 5$ \\
\hline $\begin{array}{l}\text { Calculated } \eta\left(\% \mathrm{~W}^{-1}\right)^{a} \\
\quad\left(\text { for } N=1.3 \times 10^{27} \mathrm{~m}^{-3}\right)^{b}\end{array}$ & $\begin{array}{l}134 \pm 30 \\
(134 \pm 30)\end{array}$ & $\begin{array}{l}607 \pm 35 \\
(267 \pm 15)\end{array}$ & $\begin{aligned} 378 & \pm 50 \\
(698 & \pm 90)\end{aligned}$ \\
\hline $\begin{array}{l}L_{\max }(\mathrm{cm})^{a} \\
\quad\left(\text { for } N=1.3 \times 10^{27} \mathrm{~m}^{-3}\right)^{b}\end{array}$ & $\begin{array}{l}1.5 \pm 0.2 \\
(1.5 \pm 0.2)\end{array}$ & $\begin{array}{l}5.6 \pm 1.5 \\
(7.7 \pm 2.0)\end{array}$ & $\begin{array}{l}4.1 \pm 0.8 \\
(2.6 \pm 0.5)\end{array}$ \\
\hline
\end{tabular}

${ }^{a}$ Calculated for a waveguide with an effective cross section of $\Gamma^{-1}=10 \mu \mathrm{m}^{2}$, an interface scattering loss of $0.2 \mathrm{~cm}{ }^{-1}\left(1 \mathrm{~dB} \mathrm{~cm}^{-1}\right)$ at both fundamental and second-harmonic wavelengths, and a poling field of $E=150 \mathrm{~V} \mu \mathrm{m}^{-1}$.

${ }^{b}$ Corresponding to the actual loading of the DANS-SCP used for our measurements.

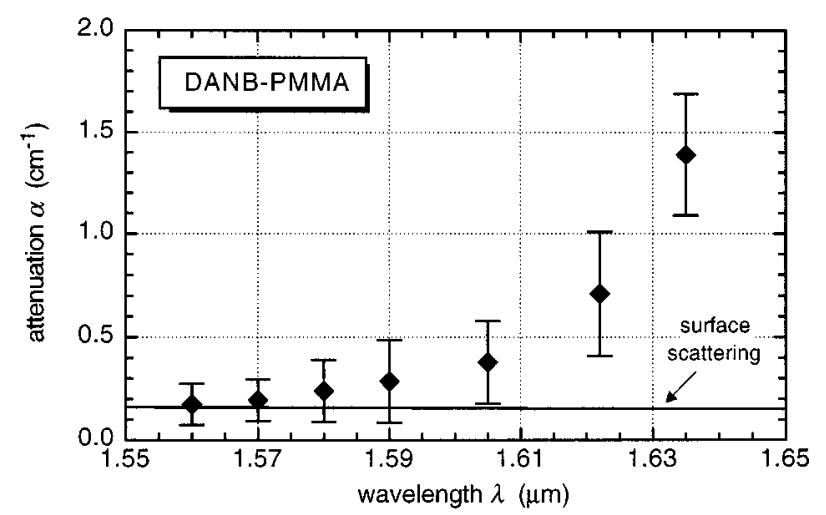

Fig. 5. Attenuation coefficient $\alpha$ of a 1.5- $\mu \mathrm{m}$ thick unpoled planar DANB-PMMA waveguide measured at $1.55-1.65-\mu \mathrm{m}$ wavelengths. Solid line, calculated surface scattering loss.

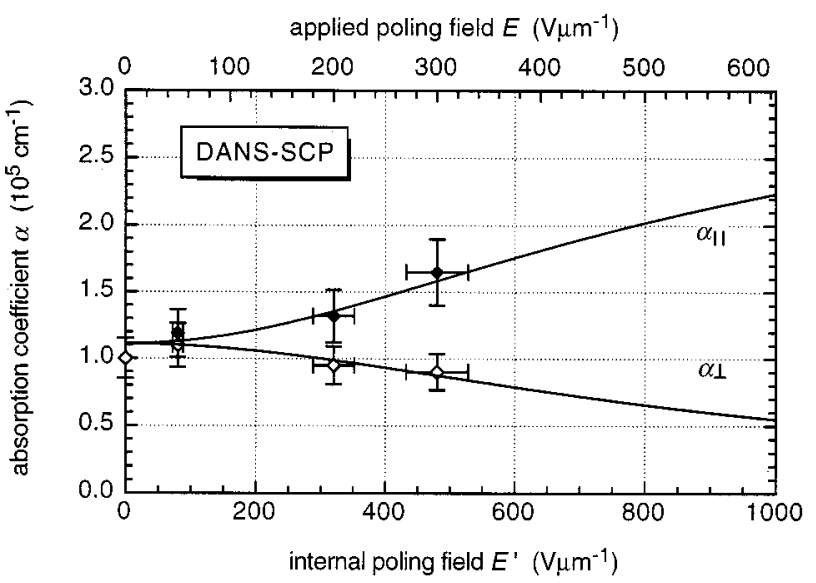

Fig. 6. Poling field dependence of the absorption coefficient for polarization parallel ( $\alpha_{\|}$, filled diamonds) and perpendicular ( $\alpha_{\perp}$, open diamonds) to the poling field, measured on in-plane poled DANS-SCP samples at a wavelength of $0.458 \mu \mathrm{m}$; curves, fits to Eqs. (12) and (13), respectively.

Both curves were fitted with one free parameter only. In Table 3 we list the $d_{33}$ coefficients for an external poling field of $150 \mathrm{~V} \mu \mathrm{m}^{-1}$, which are good estimates for the nondition, we list the fitted values for $d_{33 \text {,max }}$ that represent the theoretical limit for the nonlinearity when the isotropic model is used for fitting. The highest nonlinearity was measured for DANS-SCP and is a result of the combination of large hyperpolarizability with a relatively high chromophore loading. DANB-PMMA and DR1PMMA exhibit similar nonlinear coefficients despite the large difference in their hyperpolarizabilities (discussed in Appendix A), an effect that can be attributed to the different chromophore number densities (see Table 1).

The dependence of the nonlinearity on poling temperature was measured for DANS-SCP and DR1-PMMA in the ranges $125-145$ and $110-135^{\circ} \mathrm{C}$, respectively, and is shown in Fig. 8. It is apparent that the poling temperature is a noncritical parameter; the tolerance is of the order of degrees celsius.

\section{B. Calculation of Second-Harmonic Conversion Efficiencies in Waveguides}

In what follows, we calculate the second-harmonic conversion efficiency at $1.55 \mu \mathrm{m}$, given by Eq. (15), on the basis of the measured material parameters listed in Table 3 . We assume a channel waveguide with an effective cross section of $\Gamma^{-1}=10 \mu \mathrm{m}^{2}$, a value that is typical of annealed proton exchanged $\mathrm{LiNbO}_{3}$ waveguides. The material absorption at the fundamental is assumed to vanish, and we assume a scattering loss $\alpha_{s}$ of $0.2 \mathrm{~cm}^{-1}(1 \mathrm{~dB}$ $\left.\mathrm{cm}^{-1}\right)$ at both wavelengths. The absorption loss $\alpha_{a}(2 \omega)$ is given by the values of $\alpha_{a \text {,iso }}(2 \omega)$ listed in Table 3 , and its poling field dependence is described by Eq. (12). The poling field dependence of nonlinear-optical coefficient $d_{33}$ is given by Eq. (2), and the values of $d_{33 \text {,max }}$ are listed in Table 3.

In Fig. 9(a) we have plotted the calculated secondharmonic conversion efficiency as a function of guide length for the three polymers for an external poling field of $150 \mathrm{~V} \mu \mathrm{m}^{-1}$. The maximum attainable conversion efficiency and the corresponding guide length at this field are indicated in Table 3. Their accuracy was calculated on the basis of the experimental incertainties of $d_{33}$ and $\alpha_{2 \omega}$ as given above in Table 3. Because of its transparency, DANB-PMMA shows the highest maximum conversion efficiency, despite its small nonlinearity. This fact illustrates the importance of taking the absorption into account when one is evaluating second-harmonic figures of merit for polymers. Whereas the curves in Fig. 9(a) were calculated for the actual chromophore loading of the 
three polymers used for the measurements (listed in Tables 1 and 2), Fig. 9(b) displays the respective curves when a chromophore number density of $N=1.3$ $\times 10^{27} \mathrm{~m}^{-3}$ is assumed for all three polymers, the actual loading of DANS-SCP. Under this normalization DR1PMMA is clearly the best polymer because of its combination of large nonlinearity and low absorption. Despite its much smaller nonlinearity, the conversion efficiency attainable with DANB-PMMA is approximately a factor of 2

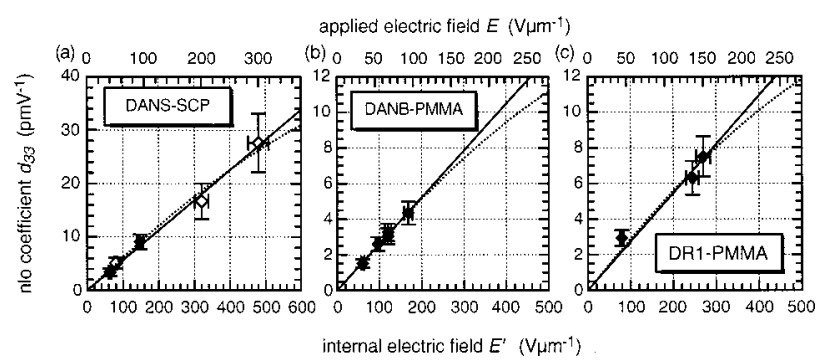

Fig. 7. Poling field dependence of the nonlinear-optical coefficient $d_{33}$ for DANS-SCP, DANB-PMMA, and DR1-PMMA. The respective poling temperatures were 135,100 , and $120^{\circ} \mathrm{C}$. Dotted curves, fits according to Eq. (2); solid curves fits according to expression (7). (a) Solid and open diamonds, data from parallelplate and in-plane poled samples, respectively. (b), (c) All data measured on parallel-plate poled samples.
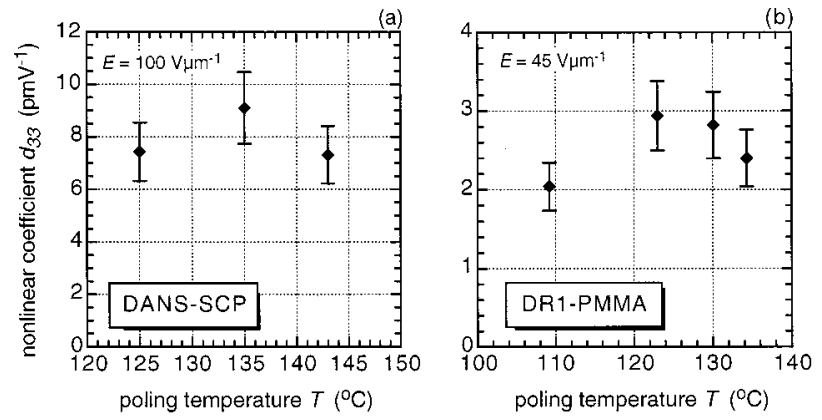

Fig. 8. Dependence of nonlinear-optical coefficient $d_{33}$ on poling temperature for DANS-SCP and DR1-PMMA.
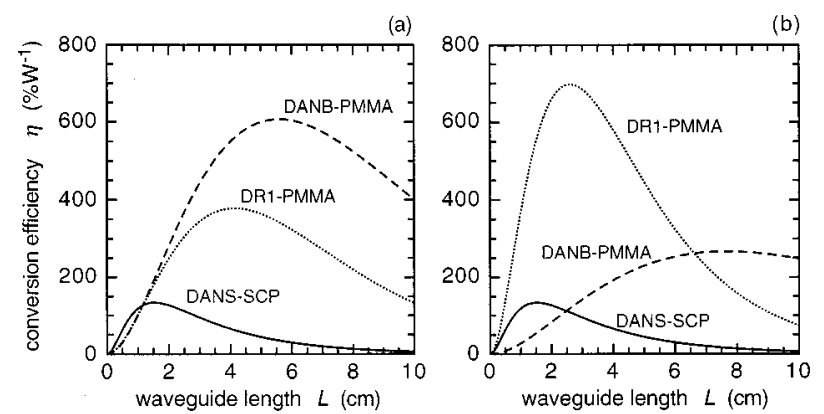

Fig. 9. Normalized second-harmonic conversion efficiency $\eta$ as a function of waveguide length $L$ calculated on the basis of the measured absorption and nonlinear-optical coefficients as listed in Table 3 for DANS-SCP, DANB-PMMA, and DR1-PMMA. (a) Dependence assuming the actual chromophore loading as listed in Table 1; (b) assuming a chromophore number density $N$ $=1.3 \times 10^{27} \mathrm{~m}^{-3}$ for all three polymers. The calculation was performed for an external poling field of $150 \mathrm{~V} \mu \mathrm{m}^{-1}$, a waveguide with an effective cross section of $\Gamma^{-1}=10 \mu \mathrm{m}^{2}$, an interface scattering loss of $0.2 \mathrm{~cm}^{-1}\left(1 \mathrm{~dB} \mathrm{~cm}^{-1}\right)$ at both wavelengths, and a fundamental wavelength of $1.55 \mu \mathrm{m}$.
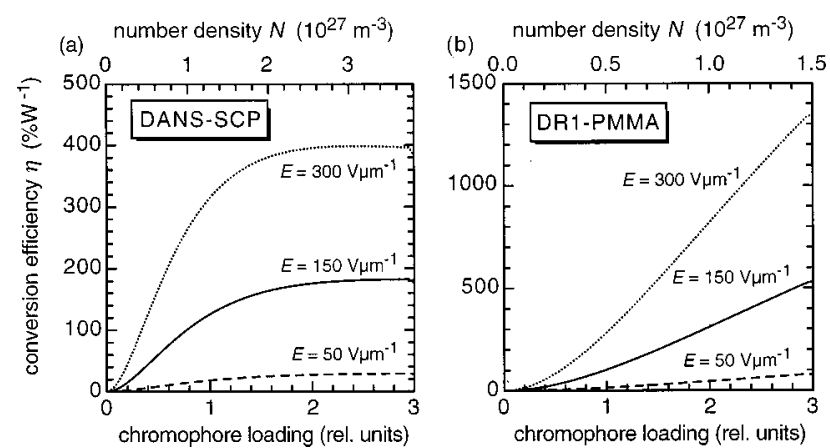

Fig. 10. Calculated normalized second-harmonic conversion efficiency $\eta$ as a function of chromophore density for DANS-SCP and DR1-PMMA for three (external) poling fields $E$. The relative units are defined such that unity corresponds to the actual loading of the chromophores in the polymers used for the measurements. The corresponding chromophore number densities $N$ are indicated on the top axes. The waveguide was assumed to be $1 \mathrm{~cm}$ long; the other parameters are identical to those in Fig. 9.
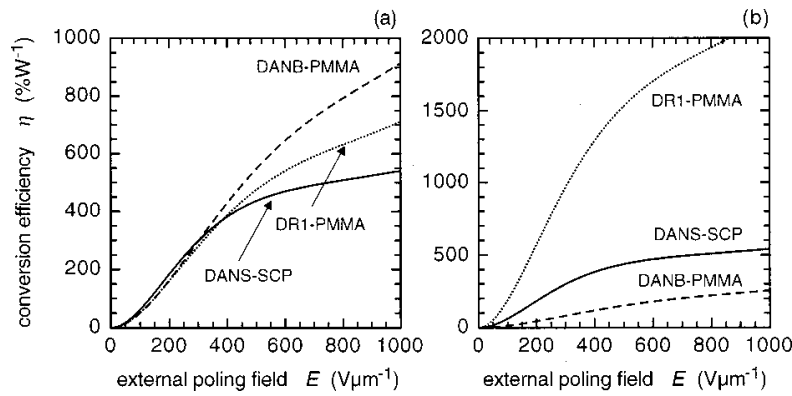

Fig. 11. Calculated normalized second-harmonic conversion efficiency $\eta$ as a function of external poling field $E$. (a) Calculated for the actual chromophore loading; (b) chromophore number density assumed to be $N=1.3 \times 10^{27} \mathrm{~m}^{-3}$ for all three polymers. The guide parameters are identical to those in Fig. 9.

larger than that of DANS-SCP; however, the maximum is reached only at an impractically long guide length.

The effect on conversion efficiency of varying chromophore concentration is shown for DANS-SCP and DR1PMMA in Figs. 10(a) and 10(b), respectively. The loading is indicated in units of multiples of the actual chromophore concentration in the polymers used for the measurements, where loading $=1$ corresponds to the values given in Table 1. The calculation was done for a waveguide of $1-\mathrm{cm}$ length and three different poling fields. The conversion efficiency saturates as a function of loading as the increase of the absorption becomes dominant over the growth of the nonlinearity. This effect is apparent for DANS-SCP, in which the chromophore concentration is nearly at the optimum level, as opposed to DR1-PMMA, for which saturation occurs at much higher chromophore loading.

The effects of varying poling field strength are illustrated in Fig. 11. In Fig. 11(a) we have calculated the normalized conversion efficiency as a function of external poling field for a guide length of $1 \mathrm{~cm}$ and the actual chromophore loading. The saturation of the conversion efficiency is due to saturation of the nonlinearity and increase of the absorption loss as a function of poling field. Figure 11(b) shows the same dependence as Fig. 11(a), assuming a chromophore loading of $N=1.3 \times 10^{27} \mathrm{~m}^{-3}$ for 
all three polymers. This calculation again emphasizes the conclusion that DR1-PMMA is the most promising of the three polymers.

\section{CONCLUSIONS}

A detailed investigation of the absorption spectra and nonlinear-optical properties is essential for assessing the potential of nonlinear polymers for guided-wave parametric processes at telecommunication wavelengths. The absorption-nonlinearity trade-off for the three polymers investigated can be described as follows: high nonlinearity-high absorption for DANS-SCP, low nonlinearity-low absorption for DANB-PMMA, and high nonlinearity-low absorption for DR1-PMMA. Obviously, DR1-PMMA exhibits the most promising properties, and DANS-SCP and DANB-PMMA are comparable despite their considerably different nonlinearities.

The conversion efficiencies for guided-wave secondharmonic generation, calculated on the basis of our experimental data, of several hundred percent per watt compare favorably with those of the best quasi-phasematched $\mathrm{LiNbO}_{3}$ waveguides. ${ }^{4,5}$ Our calculations, however, were performed for optimized waveguides, and it is yet to be proved that full advantage can be taken of the promising material properties of nonlinear polymers. So far, experimentally achieved conversion efficiencies in polymer waveguides are of the order of $0.1-1 \%$ $\mathrm{W}^{-1} \cdot 12,28,34$ To improve these values, we need to address a number of technological issues, among which are the fabrication of waveguides with good optical confinement and scattering losses smaller than $1 \mathrm{~dB} \mathrm{~cm}^{-1}$ at both wavelengths, increase of the effective poling field above
$150 \mathrm{~V} \mu \mathrm{m}^{-1}$, increase of the phase-matched guide length over $1 \mathrm{~cm}$, and design of waveguides with optimized modal overlap. Although these requirements have been shown to be attainable independently, ${ }^{18,32,35,36}$ their simultaneous fulfillment in one device still remains a challenging task.

\section{APPENDIX A: EVALUATION OF MOLECULAR PARAMETERS}

Molecular properties are usually derived from measurements in solution, whereas only few attempts to obtain data from polymer films have been made. Analysis of our absorption spectra and Maker fringe measurements can provide data for some molecular parameters in the polymer matrix that can be compared with previously published values in the literature. Their accuracy is limited by (i) experimental errors, (ii) reliability and accuracy of the models used for fitting, (iii) uncertainty of molecular parameters used for fitting purposes (given in Table 2), and (iv) uncertainty of the local electric fields. Given these restrictions, our results represent at least useful estimates.

The transition dipole moments $\mu_{01}$ from the ground to the first excited state are obtained from fitting the linear absorption spectra to the inhomogeneously broadened line profile [Eqs. (9)-(11)]. The fitted values for the three chromophores are listed in Table 4. The fitted transition dipole moments are of the same magnitude as the groundstate dipole moments $\mu_{0, Z}$ in solution (Table 2 ).

Utilizing the simple two-level model we can derive the molecular hyperpolarizability for frequency doubling $\beta_{Z Z Z}(-2 \omega, \omega, \omega)$ from quantum mechanics as

Table 4. Molecular Parameters of the Chromophores Derived from the Measurements of This Study and Comparison with Previously Published Data

\begin{tabular}{|c|c|c|c|c|}
\hline Parameter & DANS & DANB & DR1 & Reference (Method) \\
\hline $\begin{array}{l}\text { Dipole moment } \mu_{01}(\mathrm{Cm}) \\
\quad(\text { value in } \mathrm{D})\end{array}$ & $\left(2.1 \pm \underset{(6.3)}{0.2) \times 10^{-29}}\right.$ & $\begin{array}{c}\left(1.5 \pm \underset{(4.5)}{0.2) \times 10^{-29}}\right.\end{array}$ & $\begin{array}{c}(2.4 \pm \\
(7.3)\end{array}$ & $\begin{array}{l}\text { This work } \\
\text { (linear absorption of thin film) }\end{array}$ \\
\hline \multirow[t]{3}{*}{$\begin{array}{l}\text { Hyperpolarizability } \\
\qquad \beta_{Z Z Z}\left(\mathrm{~m}^{4} \mathrm{~V}^{-1}\right)^{a}\end{array}$} & $276 \times 10^{-40}$ & $68 \times 10^{-40}$ & $289 \times 10^{-40}$ & $\begin{array}{l}\text { This work } \\
\text { (Maker fringe on thin film) }\end{array}$ \\
\hline & $\begin{array}{c}244 \times 10^{-40} \\
(\text { solvent, DMSO })\end{array}$ & $\begin{array}{l}49 \times 10^{-40 b} \\
(\text { solvent, DMSO) }\end{array}$ & $\begin{array}{c}290 \times 10^{-40} \\
(\text { solvent, DMSO })\end{array}$ & $26(\mathrm{EFISH} \text { at } 1.356 \mu \mathrm{m})^{c}$ \\
\hline & $\begin{array}{c}380 \times 10^{-40} \\
\left(\text { solvent, } \mathrm{CHCl}_{3}\right)\end{array}$ & $\begin{array}{l}62 \times 10^{-40 b} \\
\text { (solvent, acetone) }\end{array}$ & $\begin{array}{l}260 \times 10^{-40} \\
(\text { solvent, dioxane) }\end{array}$ & $13(\mathrm{EFISH} \text { at } 1.907 \mu \mathrm{m})^{c}$ \\
\hline $\begin{array}{l}\text { Product } \mu \beta \\
\qquad\left(\mathrm{m}^{5} \mathrm{C} \mathrm{V}^{-1}\right)^{d}\end{array}$ & $6.7 \times 10^{-67}$ & $1.7 \times 10^{-67}$ & $8.4 \times 10^{-67}$ & This work \\
\hline \multirow{4}{*}{$\begin{array}{l}\text { Mesomeric } \\
\quad \text { moment } \Delta \mu(\mathrm{Cm}) \\
\quad(\text { value in } \mathrm{D})\end{array}$} & $5.7 \times 10^{-29}(17.1)$ & $3.6 \times 10^{-29}(10.8)$ & $3.1 \times 10^{-29}(9.1)$ & This work \\
\hline & $\begin{array}{l}5.3 \times 10^{-29} \\
6.0 \times 10^{-29}\end{array}$ & $e$ & $e$ & $\begin{array}{l}37 \text { (third-harmonic generation) } \\
37 \text { (Solvatochromic) }\end{array}$ \\
\hline & $4.0 \times 10^{-29}(12)$ & $e$ & $e$ & 38 (two-photon absorption) \\
\hline & $3.8 \times 10^{-29}(11.4)$ & $e$ & $e$ & 39 (Calculation) \\
\hline $\begin{array}{l}\text { Dipole moment } \\
\left.\mu_{1, Z}(\mathrm{Cm}) \text { (value in } \mathrm{D}\right)\end{array}$ & $8.1 \times 10^{-29}(24.3)$ & $5.9 \times 10^{-29}(17.7)$ & $5.9 \times 10^{-29}(17.8)$ & This work \\
\hline
\end{tabular}

${ }^{a}$ Uncertainty, $30-50 \%$.

${ }^{b}$ Values quoted for 4-dimethylamino-1-nitrobenzyl.

${ }^{c}$ Measured by EFISH. Values referenced to $d_{11}=0.30 \mathrm{pm} \mathrm{V}^{-1}$ at $1.064 \mu \mathrm{m}$ for quartz.

${ }^{d}$ Values for the dipole moment $\mu_{0, Z}$ taken from Table 2.

${ }^{e}$ Not applicable. 
$\beta_{Z Z Z}(-2 \omega, \omega, \omega)$

$$
=\frac{3}{2 \epsilon_{0} \hbar^{2}} \frac{\Delta \mu \mu_{01}{ }^{2} \omega_{01}{ }^{2}}{\left(\omega_{01}{ }^{2}-4 \omega^{2}\right)\left(\omega_{01}{ }^{2}-\omega^{2}\right)},
$$

where $\Delta \mu=\mu_{1, Z}-\mu_{0, Z}$ is the difference between the dipole moment of the chromophore in the excited and the ground states (mesomeric moment), $\mu_{01}$ is the transition dipole moment, and $\omega_{01}$ is the transition frequency. Using expression (7), we can calculate the molecular hyperpolarizability $\beta_{Z Z Z}(-2 \omega, \omega, \omega)$ from the fitted curves shown in Fig. 7. The $\beta$ values obtained are listed in Table 4. Apart from experimental errors, the accuracy of these $\beta$ values is directly correlated to the uncertainty of local field correction factors in expression (7). The accuracy is estimated to be of the order of $30-50 \%$. For comparison, we have also listed the hyperpolarizabilities quoted in Refs. 26 and 13, which were obtained from electric-field-induced second-harmonic (EFISH) measurements in solution. We emphasize here that one should use great caution in comparing hyperpolarizabilities obtained in solution and in solid matrices because the environment can have a pronounced effect on the value of $\beta$, which also accounts for differences in reported EFISH values in the literature if, for example, different solvents were used. Given these limitations, our values for $\beta_{Z Z Z}(-2 \omega, \omega, \omega)$ are within the range of the literature values.

Another molecular parameter, namely, the mesomeric moment $\Delta \mu$, can be derived from the two-level model with Eq. (A1) from the values fitted for $\mu_{01}, \omega_{01}$, and $\beta_{Z Z Z}$. The corresponding values are listed again in Table 4. The mesomeric moment of the same DANS-SCP had previously been derived from third-harmonic generation and solvatochromic measurements, ${ }^{37}$ two-photon absorption spectroscopy, ${ }^{38}$ and theoretical calculations. ${ }^{39}$ Again, our measurement is within the range of these values that are listed in Table 4 for comparison. Finally, we have also indicated the excited-state dipole moments $\mu_{1, Z}$.

\section{ACKNOWLEDGMENTS}

This research was supported by the U.S. Air Force Office of Scientific Research through a grant from the Jet Propulsion Laboratory. We are grateful to Akzo Nobel for providing us with the DANS-SCP material. T. Pliška and M. Canva acknowledge partial financial support provided by the Swiss National Science Foundation and by a NATO science fellowship, respectively. This research is also supported by National Science Foundation-Centre National de la Recherche Scientifique U.S.-French bilateral collaboration funds.

T. Pliška can be reached by e-mail at: tomas.pliska @ch.jdsunph.com.

*Present address, JDS Uniphase AG, Binzstrasse 17, 8045 Zürich, Switzerland; e-mail: tomas.pliska @ch.jdsunph.com.

${ }^{\dagger}$ Permanent address, Laboratoire Charles Fabry, Institut d'Optique Théorique et Appliquée, Université d'Orsay/ Paris-Sud, 91403 Orsay Cedex, France.
${ }^{\ddagger}$ Present address, Nano Technology Section, Kansai Advanced Research Center, Communications Research Laboratory, Ministry of Posts and Telecommunications, 588-2 Iwaoka, Nishi-ku, Kobe 651-2401, Japan.

\section{REFERENCES}

1. G. I. Stegeman, "Introduction to nonlinear guided wave optics," in Guided Wave Nonlinear Optics, D. B. Ostrowsky and R. Reinisch, eds. (Kluwer Academic, Dordrecht, The Netherlands, 1992), pp. 11-27.

2. K. Gallo, G. Assanto, and G. I. Stegeman, "Efficient wavelength shifting over the erbium amplifier bandwidth via cascaded second order processes in lithium niobate waveguides," Appl. Phys. Lett. 71, 1020-1022 (1997).

3. G. I. Stegeman, D. J. Hagan, and L. Torner, “ $\chi(2)$ cascading phenomena and their applications to all-optical signal processing, mode-locking, pulse compression and solitons," Opt. Quantum Electron. 28, 1691-1740 (1996).

4. M. H. Chou, I. Brener, M. M. Fejer, E. E. Chaban, and S. B. Christman, "1.5- $\mu \mathrm{m}$-band wavelength conversion based on cascaded second-order nonlinearity in $\mathrm{LiNbO}_{3}$ waveguides," IEEE Photon. Technol. Lett. 11, 653-655 (1999).

5. D. Hofmann, G. Schreiber, C. Haase, H. Herrmann, W. Grundkoetter, R. Ricken, and W. Sohler, "Quasi-phasematched difference-frequency generation in periodically poled Ti:LiNbO 3 channel waveguides," Opt. Lett. 24, 896898 (1999).

6. D. S. Chemla and J. Zyss, eds., Nonlinear Optical Properties of Organic Molecules and Crystals (Academic, Orlando, Fla., 1987).

7. H. S. Nalwa and S. Miyata, eds., Nonlinear Optics of Organic Molecules and Polymers (CRC Press, Boca Raton, Fla., 1997).

8. C. Bosshard, K. Sutter, Ph. Prêtre, J. Hulliger, M. Flörsheimer, P. Kaatz, and P. Günter, Organic Nonlinear Optical Materials (Gordon \& Breach, London, 1995).

9. D. Chen, H. R. Fetterman, A. Chen, W. H. Steier, L. R. Dalton, W. Wang, and Y. Shi, "Demonstration of $110 \mathrm{GHz}$ electro-optic polymer modulators," Appl. Phys. Lett. 70, 3335-3337 (1997).

10. K. Clays, J. S. Schildkraut, and D. J. Williams, "Phasematched second-harmonic generation in a four-layered polymeric waveguide," J. Opt. Soc. Am. B 11, 655-664 (1994).

11. T. C. Kowalczyk, K. D. Singer, and P. A. Cahill, "Anomalous-dispersion phase-matched second-harmonic generation in a polymer waveguide," Opt. Lett. 20, 2273227 (1995).

12. M. Jäger, G. I. Stegeman, S. Yilmaz, W. Wirges, W. Brinker, S. Bauer-Gogonea, S. Bauer, M. Ahlheim, M. Stählin, B. Zysset, F. Lehr, M. Diemeer, and M. C. Flipse, "Poling and characterization of polymer waveguides for modal dispersion phase-matching," J. Opt. Soc. Am. B 15, 781-788 (1998).

13. L.-T. Cheng, W. Tam, S. H. Stevenson, G. R. Meredith, G. Rikken, and S. R. Marder, "Experimental investigations of organic molecular nonlinear optical polarizabilities. 1. Methods and results on benzene and stilbene derivatives," J. Phys. Chem. 95, 10631-10643 (1991).

14. D. M. Burland, R. D. Miller, O. Reiser, R. J. Twieg, and C. A. Walsh, "The design, synthesis, and evaluation of chromophores for second-harmonic generation in a polymer waveguide," J. Appl. Phys. 71, 410-417 (1992).

15. M. Jäger, V. Ricci, W. R. Cho, M. Canva, and G. I. Stegeman, "Advantages of modal-dispersion phasematching and material requirements for polymeric devicesusing efficient second harmonic generation at telecommunication wavelengths," Mater. Res. Soc. Symp. Proc. 488, 179-191 (1998).

16. A. Otomo, M. Jäger, G. I. Stegeman, M. Flipse, and M. Diemeer, "Key trade-offs for second harmonic generation in poled polymers," Appl. Phys. Lett. 69, 1991-1993 (1996).

17. A.-C. Le Duff, V. Ricci, T. Pliška, M. Canva, G. I. Stegeman, 
K. P. Chan, and R. J. Twieg, "Importance of chromophore environment on the near infrared absorption of polymeric waveguides," Appl. Opt. 39, 947-953 (2000).

18. M. Jäger, G. I. Stegeman, M. C. Flipse, M. Diemeer, and G. Möhlmann, "Modal dispersion phase matching over $7 \mathrm{~mm}$ length in overdamped polymeric channel waveguides," Appl. Phys. Lett. 69, 4139-4141 (1996).

19. Q. Zhang, M. Canva, and G. I. Stegeman, "Wavelength dependence of 4-dimethylamino-4' - nitrostilbene polymer thin film photodegradation," Appl. Phys. Lett. 73, 912-914 (1998).

20. K. D. Singer, M. G. Kuzyk, and J. E. Sohn, "Second-order nonlinear-optical processes in orientationally ordered materials: relationship between molecular and macroscopic properties," J. Opt. Soc. Am. B 4, 968-976 (1987).

21. C. P. J. M. van der Vorst and S. J. Picken, "Electric field poling of acceptor-donor molecules," J. Opt. Soc. Am. B 7, 320-325 (1990).

22. C. J. F. Bottcher, Theory of Electric Polarization (Elsevier, Amsterdam, 1973)

23. K. D. Singer and A. F. Garito, "Measurements of molecular second order optical susceptibilities using dc induced second harmonic generation," J. Chem. Phys. 75, 3572-3580 (1981).

24. A. Skumanich, M. Jurich, and J. D. Swalen, "Absorption and scattering in nonlinear optical polymeric systems," Appl. Phys. Lett. 62, 446-448 (1993).

25. P. K. Tien, "Light waves in thin films and integrated optics," Appl. Opt. 10, 2395-2413 (1971).

26. K. D. Singer, J. E. Sohn, L. A. King, H. M. Gordon, H. E. Katz, and C. W. Dirk, "Second-order nonlinear-optical properties of donor- and acceptor-substituted aromatic compounds," J. Opt. Soc. Am. B 6, 1339-1350 (1989).

27. M. Jäger, G. I. Stegeman, G. R. Möhlmann, M. C. Flipse, and M. J. B. Diemeer, "Second harmonic generation in polymeric channel waveguides using modal dispersion," Electron. Lett. 32, 2009-2010 (1996).

28. W.-R. Cho, V. Ricci, T. Pliška, M. Canva, and G. I. Stegeman, "Second-harmonic generation in reactively-ion etched, Disperse Red 1 polymer waveguides at telecommunication wavelengths," J. Appl. Phys. 86, 2941-2944 (1999).

29. T. Pliška, V. Ricci, L. Friedrich, A.-C. Le Duff, M. Canva, G. I. Stegeman, P. Raimond, and F. Kajzar, "Polymer waveguides for $\chi^{2}: \chi^{2}$-cascading at telecommunication wavelengths," (presented at the 9th European Conference on Integrated Optics, Turin, Italy, April 14-16, 1999).

30. P. A. M. Steeman, F. J. J. Maurer, and J. van Turnhout, "Dielectric properties of blends of polycarbonate and acrylonitrile-butadiene-styrene copolymer," Polym. Eng. Sci. 34, 697-706 (1994).

31. K. Mazur, "More data about dielectric and electret properties of poly(methyl methacrylate)," J. Phys. D 30, 13831398 (1997).

32. A. Otomo, G. I. Stegeman, W. H. G. Horsthuis, and G. R. Möhlmann, "Strong field, in-plane poling for nonlinear optical devices in highly nonlinear side chain polymers," Appl. Phys. Lett. 65, 2389-2391 (1994).

33. D. A. Roberts, "Simplified characterization of uniaxial and biaxial nonlinear optical crystals: a plea for standardization of nomenclature and conventions," IEEE J. Quantum Electron. 28, 2057-2074 (1992).

34. Y. Shuto, T. Watanabe, S. Tomaru, I. Yokohama, M. Hikita, and M. Amano, "Quasi-phase-matched second-harmonic generation in diazo-dye-substituted polymer channel waveguides," IEEE J. Quantum Electron. 33, 349-357 (1997).

35. T. Pliška, V. Ricci, A.-C. Le Duff, M. Canva, P. Raimond, F. Kajzar, and G. I. Stegeman, "Low loss polymer waveguides fabricated by plasma etching for nonlinear-optical devices at telecommunication wavelengths," in Conference on Lasers Electro-Optics (CLEO/US), 1999 OSA Technical Digest Series (Optical Society of America, Washington, D.C., 1999), pp. 313-314

36. W. Wirges, S. Yilmaz, W. Brinker, S. Bauer-Gogonea, S. Bauer, M. Jäger, G. I. Stegeman, M. Ahlheim, M. Stählin, B. Zysset, F. Lehr, M. Diemeer, and M. C. Flipse, "Polymer waveguides with optimized overlap integral for modal dispersion phase-matching," Appl. Phys. Lett. 70, 3347-3349 (1997).

37. W. E. Torruellas, R. Zanoni, G. I. Stegeman, G. R. Möhlmann, E. W. P. Erdhuisen, and W. H. G. Horsthuis, "The cubic susceptibility dispersion of alkoxy-nitro-stilbene (MONS) and di-alkyl-amino-nitro-stilbene (DANS) side chain susbtituted polymers: comparison with the twolevel model," J. Chem. Phys. 94, 6851-6856 (1991); Erratum, J. Chem. Phys. 96, 1662 (1992).

38. M. Cha, W. E. Torruellas, G. I. Stegeman, W. H. G. Horsthuis, G. R. Möhlmann, and J. Meth, "Two photon absorption of di-alkyl-amino-nitro-stilbene side chain polymer," Appl. Phys. Lett. 65, 2648-2650 (1994).

39. D. Beljonne, J. L. Brédas, M. Cha, W. E. Torruellas, G. I. Stegeman, J. W. Hofstraat, W. H. G. Horsthuis, and G. R. Möhlmann, "Two-photon absorption and third-harmonic generation of di-alkyl-amino-nitro-stilbene (DANS): a joint experimental and theoretical study," J. Chem. Phys. 103, 7834-7843 (1995). 